Article

\title{
Conceptualising Sustainability Using a Cognitive Mapping Method
}

\author{
Patrina Whyte and Geoffrey Lamberton * \\ School of Business and Tourism, Southern Cross University, Bilinga, QLD 4225, Australia; \\ patrina087@hotmail.com \\ * Correspondence: glambert@scu.edu.au
}

Received: 22 January 2020; Accepted: 3 March 2020; Published: 5 March 2020

check for updates

\begin{abstract}
Many different interpretations of the meaning of sustainability has the potential to cause dilution of meaning, as well as ambiguity and confusion, and a reduction in the use of sustainability as a relevant global objective. In this research, we examine these different interpretations using a cognitive mapping method, where 12 sustainability experts provide their own unique conceptualisations of sustainability. Our research objective is to develop a conceptual tool that explains differences in these many sustainability meanings. The experts' conceptualisations reveal worldviews that are predominantly anthropocentric, but which also contain principles consistent with the sustaincentrism paradigm. We observe that each expert's worldview, together with the assumed primary objective of sustainability, and the type of actions recommended to achieve sustainability, are central to understanding the diversity of sustainability conceptualisations. This insight leads to the development of a framework that infers sustainability can be conceptualised to consist of three distinct layers consisting of a core objective, or what is to be sustained; a worldview that underpins the conceptualisation; and actions aimed at achieving sustainability. By clarifying the multiple layers contained within sustainability conceptualisations, competing and contested versions of sustainability can be clarified within a common theoretical framework. The sustainability framework should also assist educators and students navigate through the multiplicity of sustainability meanings, and enable new context-specific definitions to be developed, such as those used in business and government.
\end{abstract}

Keywords: cognitive map; sustainability conceptualisation; worldview; sustaincentrism

\section{Introduction}

Although there is an agreement that sustainability is a desirable state [1], there is strong evidence of a lack of progress towards global sustainability [2]. One possible cause of lack of progress is the absence of clarity of definition, which precludes a clearly defined set of sustainability goals and actions to achieve these goals [3]. However, there are divergent views as to whether the diversity of meaning is problematic or beneficial to sustainability remaining a globally relevant objective and expression of concern for deterioration in the natural environment.

Giovannucci and Potts [4] consider the diversity of meanings of sustainability as being both positive and essential for all big ideas, noting that important life concepts, such as democracy, justice and welfare do not have universally agreed definitions [5]. This positive view of diversity suggests contradiction and difference promotes vigorous and fertile discussion, new thinking, discoveries and innovations [6], leading to creative solutions to an inherent conceptual contradiction [7]. The diverse range of meanings results in sustainability being a flexible concept with the scope for context-specific interpretations that enable the resolution of conflicting goals at, for example, a local level [8]. Manderson [9] suggests this diversity of meaning reflects many valid versions of sustainability, which can co-exist. 
However, it has also been proposed that the diversity of meanings of sustainability creates a hurdle to constructive discussion, due to confusion [10] which causes misunderstanding between various interest groups [11]. As sustainability is an ambiguous concept, it is difficult to determine a particular problem as being a sustainability problem [12], and hence, in need of a multidisciplinary solution. This ambiguity and misconception of sustainability meaning may lead to inappropriate management practices and problems formulating policy and action [3], hindering incremental progress towards sustainability [13].

Further, there are concerns the underlying principles of sustainability are being eroded by interpretations which vary in intent, scope and severity, thus, diluting the concept's meaning [14]. This is evidenced by the use of the term sustainability to describe anything exceptional [15], or merely desirable [14]. The complexity of meaning is further complicated by internal contradictions contained within allied concepts, such as sustainable development [16,17]. Given this lack of clarity, vested interest groups use the sustainability label to mask actions that are neither sustainable nor developmental [18], but rather are highly self-serving [19]. Inherent contradictions in the range of sustainability definitions, and attempts to resolve this, have only accelerated the growth of new interpretations [20]. Connelly [19] (p. 262) emphasises that sustainable development is essentially contested rather than ambiguous, and the need to recognise a "multiplicity of sustainabilities" and the "intellectual legitimacy of alternative interpretations".

The objective of this research is not to contribute more, or select preferred definitions of sustainability, but rather to develop a conceptual tool that explains the sources of difference underpinning the multitude of sustainability meanings, to facilitate increased understanding and ultimately increase the effectiveness of action taken to achieve sustainability. Towards this end, this research, drawing inspiration from Byrch et al. [5], utilises a cognitive mapping method to explain differences in how sustainability is conceptualised. This leads to an examination of the worldviews that underpin each expert's conceptualisation and the development of a framework to clarify sources of conceptual difference. There is an enormous body of literature covering sustainability and its many contested meanings. This research draws predominantly from sustainability literature within business and management, supplemented by literature from sustainability education, a focus that matches the backgrounds of the expert participants in this study.

\section{Diverse Views of Sustainability}

In this section, we provide the theoretical foundation for our study of how sustainability is conceptualised, by drawing substantially from recent literature regarding different views that underly sustainability. We begin with the traditional multidisciplinary view and its fundamental limitation, followed by an overview of research that explains sources of differences in sustainability meanings. We discuss relevant moral, cognitive and paradigmatic elements, but avoid an extensive comparison of the multitude of sustainability definitions, as acceptance of this diversity is the starting point for this study. Our selection of studies included in this review, reflects the emphasis on the importance of the underlying worldview to any sustainability conceptualisation [5], and leads to a discussion of three alternative worldviews that are used extensively in our analysis of the sustainability experts' cognitive maps.

The traditional multidisciplinary view of sustainability is that it consists of economic, social, cultural and environmental elements [21]; however, there is no agreement of the relative importance of each element, and considerable tension exists among different interest groups as to which of these elements should be prioritised. Byrch et al. [5] suggest that different emphases on specific elements underpin different sustainability interpretations, and that these different emphases reflect the underlying view of humankind's relationship with nature. Beyond this traditional view is the recognition that differences in sustainability meaning and interpretation occur, due to differences in scale, change processes, temporal, and spatial contexts [22]. Scale concerns the application of sustainability from the individual through to a global scale, and all relevant scales in between, 
including community, organisational, regional and national levels. An example of the relevance of scale to different sustainability meaning would be a view that ecosystem health should take precedence over other elements of sustainability at a regional level given it supports entire communities, whereas, social wellbeing may be considered the dominant element of sustainability at the household level. Hence, the scale is relevant to how tension is resolved, particularly where the perception is that the traditional economic, environmental and social elements of sustainability are competing elements.

The change process refers to the distinction between two possible transformation pathways; one being the elimination of current institutions and replacement with new institutions designed for sustainability; versus an incremental reform process where current institutions are reformed over time to conform to sustainability principles [22]. The temporal context refers to intergenerational issues, such as a fair allocation of resources between current and future generations, which is a normative element central to the World Commission on Environment and Development's (WCED) famous needs-based definition of sustainability [23]. The spatial context concerns intragenerational equity and the fair allocation of resources between members of the current generation [22]. Given the wicked nature of global poverty over the very long term, proposed solutions vary enormously.

Relevant to the sustainability change process, is the description of sustainability using the metaphor of a journey rather than a predefined outcome, where the transformation to sustainability is pursued incrementally over the long term by taking many (usually) small steps. Kioupi et al. [24] view sustainability as an aspirational future world transformed by the Sustainable Development Goals, rather than a predetermined state. More concerningly, Milne et al. [25] view the metaphorical journey towards sustainability as an insufficient incremental change towards a goal that can never be reached without radical intervention. Agreeing with Milne, Painter-Moreland et al. [26] view the journey metaphor as inherently dangerous as it provides the business sector with the flexibility to make a minimal immediate change, whilst appearing, with the aid of greenwashed sustainability reports, to be making significant progress towards sustainability. A contrasting view is that this inherent flexibility enables sustainability meaning to adapt to the prevailing conditions as it is not a rigid system of rules or predetermined outcome [27].

Hahn et al. [28] link conceptual ambiguity to the divide between the belief in a unitary truth versus acceptance of paradoxical thinking. Unitary truth requires tension between sustainability's competing elements to be reconciled and eliminated, which is typically achieved by defaulting to the business-case approach, forcing sustainability projects to meet pre-set economic returns [28]. Underpinning the business case approach is the assumption that well-being is material wealth [26]; an assumption that would lead to an interpretation of the WCEDs needs-based definition of sustainability, as the need for material wealth. A holistic or integrative view applies paradoxical thinking to accommodate this tension by focusing on the interconnections between each sustainability element [29], integrated [22] into a holistic vision of sustainability that identifies preferred developmental paths that ensure intergenerational justice $[5,24,30]$.

Given the breadth and complexity of sustainability meanings, it is unsurprising that it has become a ... "a deeply normative issue often involving conflicting worldviews and contested pathways" [31] (p. 2). This moral dimension is reflected in inter and intra generational concerns discussed above in the temporal and spatial contexts, as well as, for example, in the theoretical development of the concepts of social justice and social sustainability [23].

The fundamental divide between anthropocentric and ecocentric ethics is another cause of diverse interpretations of sustainability. Environmental activists often emphasise the ecocentric moral imperative to preserve natural systems, whereas, anthropocentrism leads to the prioritisation of economic development, and for example, definitions of sustainability that are compatible with continued economic growth. Within business, an altruistic motivation to strive for sustainability because it is the right thing to do, contrasts with enlightened self-interest [28], where sustainability is pursued because it is believed to be good for business, which suggests that actions to achieve sustainability will cease if the financial analysis suggests it is unprofitable. The anthropocentric belief in 
human exceptionalism underpins this more instrumental, business-case view of sustainable (economic) development [30]; whereas, privileging natural systems is an ecocentric view aimed at emancipation from human-caused environmental destruction.

Moral dimensions of sustainability are central to our worldview, which are defined as the "... constellations of beliefs, values and concepts that give shape and meaning to the world a person experiences and acts within" [32] (p. 75). Bawden [33], whilst distinguishing the disparate worldviews produced by technocentrism, corporatism and libertarianism versus ecocentrism, communitarianism and egalitarianism, argues that both cognitive belief and normative positions are central to different worldviews, and

“(g)iven that our worldviews ... reflect our most fundamental belief positions, it is not at all surprising that we hold to them with such conviction. It is equally understandable that communication between people with different worldviews, is typically so distorted" [33] (p. 8)

Kitchener [34] distinguishes cognition (ways of knowing) from meta-cognition (knowing about knowing) from epistemic cognition (knowing about the nature of knowledge). Epistemic cognition enables us to understand that the worldview that we hold provides the context for knowledge, without which we will not be able to challenge and where needed, change our worldview to enable, for example, transformation to sustainability. Van Egmond et al. [35] (p. 865) believe that unsustainability is rooted in unstable values contained within our worldviews and inappropriate societal value orientations, requiring the right balance between "material and immaterial and between individualist and collective values". Hedlund-de Witt [36] describes an enhanced understanding of worldviews and inherent values as essential to the path towards sustainability. Byrch et al. [5] (p. 28), expressing concern that extreme diversity of meaning hinders progress towards sustainability, consider the fundamental reason for diversity of interpretation to be differences in underlying environmental worldviews or "individuals' fundamental beliefs about humanity's proper relationship with nature", a view also supported by Bonnett [37].

This discussion of different views of sustainability, reveals the worldview on which any definition is necessarily based, as a potential source of tension between competing versions of sustainability. Gladwin et al. [38] (p. 876), noting that the sustainability construct is " ... infused with ... considerable moral thickness", and that human-environment relationships are commonly viewed through the alternate lenses of technocentrism and ecocentrism, offer an alternate and centred worldview that they label the 'sustaincentrism' paradigm. An overview of these three paradigms is provided in Table 1.

Table 1. The technocentrism, sustaincentrism and ecocentrism paradigms.

\begin{tabular}{|c|c|c|}
\hline Technocentrism & Sustaincentrism & Ecocentrism \\
\hline $\begin{array}{l}\text { - Humans are separate from nature, } \\
\text { which they manage for human use. } \\
\text { Nature consists of resources for } \\
\text { human use. } \\
\text { - A utilitarian and anthropocentric } \\
\text { ethic underpins the use of } \\
\text { cost-benefit environmental } \\
\text { decision making. } \\
\text { Intergenerational responsibility is } \\
\text { met by continued growth and } \\
\text { technological advancement. }\end{array}$ & $\begin{array}{l}\text { Humans are superior to other } \\
\text { species.Environmental } \\
\text { preservation is essential for } \\
\text { human survival. } \\
\text { Environmental preservation } \\
\text { is essential for } \\
\text { human survival. } \\
\text { Eco-humanist ethic based on } \\
\text { stewardship of nature for the } \\
\text { benefit of humans. } \\
\text { Act for the good of humans } \\
\text { and non-humans, and } \\
\text { specifically } \\
\text { future generations. }\end{array}$ & $\begin{array}{l}\text { Humans are part of and } \\
\text { dependent on nature. } \\
\text { Nature has intrinsic value } \\
\text { separate from human } \\
\text { instrumental use. } \\
\text { An ecocentric ethic } \\
\text { prioritises the preservation } \\
\text { of the holistic } \\
\text { biotic community. }\end{array}$ \\
\hline
\end{tabular}


Within the dominant technocentric paradigm, humankind is viewed as separate from the natural world; decision-making is anthropocentric and focused on economic consequences; and economic growth and technological innovation resolve problems of environmental decline [38]. An ecocentric ethic is based on a belief that nature has intrinsic value independent of human use. Leopold [39] described this ecocentric ethic as the need to preserve the integrity, stability and beauty of nature, emphasising an ethic to not harm nature. The ecocentric view sees everything as connected to everything else, with humankind as part of and totally dependent on nature.

Gladwin et al. [38] propose sustaincentrism as an alternative to the technocentric and ecocentric paradigms. Sustaincentrism emphasises human stewardship of Earth's many species to ensure human survival and wellbeing, acknowledging humankind's intellectual superiority to other species. Although anthropocentric, a sustaincentric ethic requires doing good for both human and non-human nature [38]. This includes a commitment to both intergenerational equity, that is the responsibility not to compromise the ability of future generations to meet their needs, and intragenerational equity to ensure basic needs for all humanity are met. This distinction between technocentrism, ecocentrism and sustaincentrism is used later in this paper to distinguish the sustainability conceptualisations provided by the 12 experts.

Next, we discuss the cognitive mapping method used to determine how 12 experts conceptualise sustainability, and then examine the worldviews underpinning these conceptualisations drawing on Gladwin et al's sustaincentrism paradigm.

\section{Methodology}

This research follows Byrch et al. [5] by using a cognitive mapping method to reveal each participant's understanding of sustainability. 'Cognitive' refers to the mental activities that deal with abstract information, its representation, and the way we access information from memory [40]. In this research, we access the participant's knowledge of sustainability by asking them to produce cognitive maps of what sustainability means to them, as ... "a person's knowledge of the meaning of sustainable development is the result of their culture and experience filtered by their worldview" [5] (p. 30).

Cognitive mapping is a "technique that captures an individual's view of a particular issue in a graphical representation" [41] (p. 114). It allows participants to express their understanding of the phenomenon in a multi-dimensional and individually specific way, utilising a combination of words, phrases, relationships and ideas which are linked to describe the phenomenon, and is thus, restricted only by the participant's own ability to convey ideas using their written, creative and verbal skills. Cognitive maps are "hypothesised knowledge structures embodying people's assumptions, beliefs, "facts" and misconceptions about the world" [42] (p. 1), which consist of conceptual representations and malleable hierarchies of these representations which guide our interpretation, decision making and behaviour and demonstrate knowledge and competence regarding the phenomena [43].

Following Byrch et al. [5], the cognitive mapping method used in this research utilises a low-directed technique with minimal instructions allowing participants' discretion [43] as they choose how to identify and organise concepts they consider to be critical to the subject. Low-directed techniques have been described as content-rich and process-open, due to the variety of original content that participants can input, as well as allowing participants to determine many aspects of the flexible structure [43]; such as the number of and label given to each concept; how many concept cards are used; how cards are arranged to show the interconnection between concepts; and time taken to complete this task [42]. Participants in this research described to the researcher their interpretations of sustainability (which were recorded) using the arranged concept cards to visually represent each completed cognitive map (which were photographed).

This open-ended approach is suitable for smaller sample sizes, due to flexibility in time required to complete the task [42]. This flexibility led to significant variation in the content, detail and time spent preparing each cognitive map. Ten interviews were conducted face-to-face in five Australian cities, and two were online interviews ranging in time from seven minutes (for one interview) to 57 minutes, 
producing cognitive maps consisting of between two to twenty-five concept cards. The number of words written on the concept cards varied from 6 to 228. This variation in time, the number of concept cards used and word count shows that one participant felt that sustainability could be conceptualised quickly with minimal content. In contrast, others required many concept cards and approximately one hour to prepare and describe their conceptualisation.

Experts were drawn from business, educational and not-for-profit organisations. Business organisations comprised Australian companies selected from the ASX Top 100 which had achieved at least one of the following: Either a Global Reporting Initiative rating of 'A+'; or inclusion in the Dow Jones Sustainability Index; or receipt of a sustainability award in the previous five years. Sustainability educators consisted of high school teachers, TAFE teachers and university lecturers who teach specific subjects connected to sustainability. Not-for-profit organisations included social and environmental NGOs and government departments and were selected if they had an advertised goal of sustainability, including the promotion of sustainability initiatives or disclosing information regarding sustainability initiatives in their promotional material or websites. Once the organisation was identified, the person within the organisation most involved in sustainability initiatives (for example the Sustainability Manager in a corporation or university, or the sustainability teacher in a tertiary institution or high school) was invited to participate in the research. Age, gender, ethnicity and experience of each participant were not considered when selecting participants. From the list of available experts, priority was given to those in closest proximity to the researchers, as well as those located in capital cities, and hence, readily accessible for interview.

Participants were read instructions regarding the preparation of their concept cards, and were given the opportunity to orally describe their understanding of sustainability as depicted by their cognitive maps. The interviewer only asked further questions where needed to clarify the cognitive maps produced.

The following instructions were read to participants in each face-to-face interview -

Please take as many of these blank cards as you like and write aspects key to the concept of sustainability. Please arrange your cards in a way that expresses your understanding of sustainability, including any relationships or connections that may exist. Feel free to explain your choice of concepts, or the relationships between them.

Once the cognitive map was arranged and completed by the participant, the concept cards were photographed. In the online interviews, the participants used the Collaborate virtual meeting platform where text boxes were substituted for concept cards, and the sessions were recorded. Some cognitive maps include arrows and/or numbers to depict the sequential flow of ideas. All participants orally interpreted their maps and identified the sequential flow from one concept card to the next.

The cognitive maps are reproduced from photos, with additional sequencing, arrows and text added drawn from each expert's oral interpretation. Thematic analysis of the maps followed a sequential process [44] involving the initial identification of code words and the frequency of repetition of these codes by the 12 experts. These codes were then condensed into basic themes by grouping based on conceptual commonality, and then refined into higher order and more interpretive themes. Further, each map was examined for the underlying worldview of the expert identified by the use of language reflecting established sustainability principles and practices, and ethical concepts. Three cognitive maps are presented in the next section, followed by an analysis of each expert's worldview and a summary of the sustainability themes included in the 12 cognitive maps (see Supplementary Materials).

\section{Results}

Cognitive maps A, B, and C present the sustainability conceptualisations of three expert participants in this research. It is not considered necessary to reproduce all 12 cognitive maps in this paper as the sample provided is representative of the diversity of size, nature and content of the experts' visual representations of what sustainability means to them. This diversity was not found to be due to the 
specific sector (business, education or not-for-profit) in which the expert is employed; hence, there is no inter-sector analysis provided. Cognitive maps A, B, and C represent a combination of the visual maps produced by each of these participants, with arrows and headings added based on each expert's oral interpretation of their map. The remaining nine cognitive maps are available online.

Cognitive Map A was produced by Expert B (refer Table 2) from the business sector and was chosen to present in this paper as it is one of the more detailed cognitive maps. Cognitive Map B was produced by Expert G (refer Table 2) from the education sector and was chosen as this expert used a different language to conceptualise sustainability relative to the other experts. Cognitive Map $\mathrm{C}$ was produced by Expert $\mathrm{F}$ (refer Table 2) from the education sector and is depicted here as the structure of this map with three distinct layers of meaning significantly influenced the sustainability conceptualisation framework produced later in this paper (Figure 1).

Cognitive map A

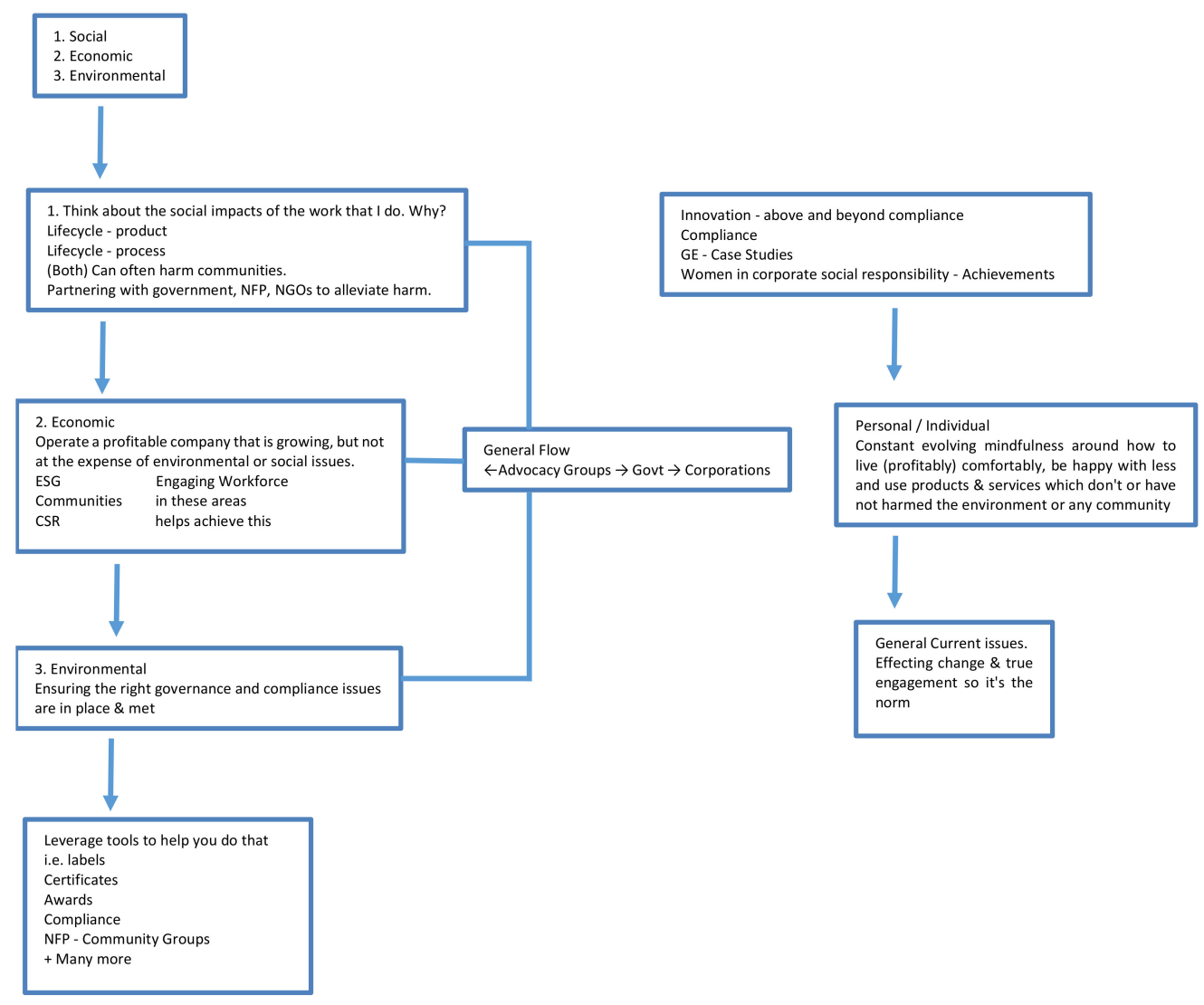

Figure 1. Cognitive Map A. Cognitive map prepared by Expert B. 
Table 2. Ranking of experts along sustainability paradigm continuum.

\begin{tabular}{|c|c|c|c|}
\hline Expert & Sustainability Knowledge & Ethical Values & $\begin{array}{c}\text { Rank } \\
1=\text { Ecocentrism } \\
12=\text { Anthropocentrism }\end{array}$ \\
\hline A & $\begin{array}{c}\text { Efficient management. } \\
\text { Compliance with standards. } \\
\text { Business case. } \\
\text { Closed loop model. } \\
\text { Redesign management structures. } \\
\text { Embed sustainability in organisational philosophy and } \\
\text { culture }\end{array}$ & $\begin{array}{c}\text { Incentivise ethical behaviour. } \\
\text { Connect what is right to efficiency } \\
\text { savings. }\end{array}$ & $\begin{array}{l}7 \\
\text { Managerial focus; human-centred } \\
\text { ethic; strong commitment to } \\
\text { sustainability. }\end{array}$ \\
\hline B & $\begin{array}{c}\text { Economic growth. } \\
\text { Innovation. } \\
\text { Efficient governance. } \\
\text { Compliance. } \\
\text { Lifecycles. } \\
\text { Engagement and partnership. }\end{array}$ & $\begin{array}{l}\text { Social responsibility. } \\
\text { Ethic of doing no harm. } \\
\text { Conservation ethic. } \\
\text { Mindfulness of social and } \\
\text { environmental impacts. }\end{array}$ & $\begin{array}{l}6 \\
\text { Emphasis on strong governance, } \\
\text { compliance and growth. Strong } \\
\text { social ethic with evidence of } \\
\text { environmental responsibility. }\end{array}$ \\
\hline C & $\begin{array}{l}\text { Balance current versus future needs. } \\
\text { Finite resource limits. } \\
\text { Dynamic, changing external environment. } \\
\text { Long term goal. }\end{array}$ & Intergenerational responsibility. & $\begin{array}{c}8 \\
\text { Anthropocentric view of } \\
\text { sustainability with } \\
\text { acknowledgement of impact on } \\
\text { future generations. }\end{array}$ \\
\hline $\mathrm{D}$ & $\begin{array}{l}\text { Managerial efficiency and HRM as a path to } \\
\text { sustainability. } \\
\text { Resource efficiency and sufficiency of consumption. } \\
\text { Sustainability reporting. } \\
\text { Education as a critical enabler. } \\
\text { Questioned fungibility of natural resources for } \\
\text { human-made resources and problems caused by } \\
\text { financial measurement of nature. }\end{array}$ & $\begin{array}{l}\text { Responsibility to people. } \\
\text { Care for staff. } \\
\text { Inclusiveness. }\end{array}$ & $\begin{array}{c}10 \\
\text { Managerial focus with a strong } \\
\text { social ethic. }\end{array}$ \\
\hline E & $\begin{array}{c}\text { Systems thinking. } \\
\text { Business strategy. } \\
\text { Ecological economics. } \\
\text { Green business. } \\
\text { Compliance with environmental standards. } \\
\text { Global reporting initiative. } \\
\text { Stakeholder management. }\end{array}$ & $\begin{array}{l}\text { Corporate social responsibility. } \\
\text { Ethical management. } \\
\text { Emphasised responsibility in the } \\
\text { workplace and responsible } \\
\text { leadership. } \\
\text { Human focused ethic. }\end{array}$ & $\begin{array}{l}\text { 4 } \\
\text { Anthropocentric ethic; social } \\
\text { responsibility; focus on the use of } \\
\text { business sustainability tools. }\end{array}$ \\
\hline$F$ & $\begin{array}{l}\text { Holistic systems. } \\
\text { Innovation, collaboration, creativity and reflection. } \\
\text { Ways of thinking. } \\
\text { Community engagement. } \\
\text { Adaptation and transformation. } \\
\text { Needs-based definition. }\end{array}$ & $\begin{array}{l}\text { Social responsibility. } \\
\text { Responsible leadership. } \\
\text { Human connection with nature. } \\
\text { Social justice. }\end{array}$ & $\begin{array}{l}2 \\
\text { Social and environmental ethic; } \\
\text { dependence on the holistic system } \\
\text { of nature; sustainability as } \\
\text { transformational change. }\end{array}$ \\
\hline G & $\begin{array}{l}\text { Focus on soft skills of building relationships, } \\
\text { connections, mutuality and reflection. } \\
\text { Holistic four-dimensional view of sustainability. } \\
\text { Place-based and context-specific. } \\
\text { Learning oriented change process. }\end{array}$ & $\begin{array}{l}\text { Social wellbeing.Social equity. } \\
\text { Mutually beneficial stakeholder } \\
\text { relationships. }\end{array}$ & $\begin{array}{c}5 \\
\text { Anthropocentric ethic emphasising } \\
\text { social skills and human needs. }\end{array}$ \\
\hline $\mathrm{H}$ & $\begin{array}{c}\text { Viewed nature as capital stock. } \\
\text { Efficiency. } \\
\text { Interconnection. } \\
\text { Holistic, systematic, multidisciplinary, systems } \\
\text { thinking. } \\
\text { Specific action required to achieve intergenerational } \\
\text { equity. } \\
\text { Indigenous cultural beliefs. }\end{array}$ & $\begin{array}{l}\text { Equality of humans and the } \\
\text { environment. } \\
\text { Intergenerational equity. }\end{array}$ & 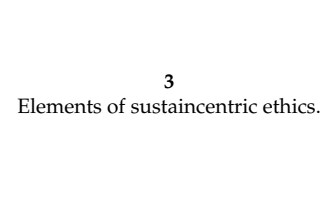 \\
\hline I & $\begin{array}{c}\text { Balance of nature. } \\
\text { Harmony. } \\
\text { Economic growth exceeds ecological limits. } \\
\text { Consumerism and hyper-consumption. } \\
\text { An economic growth-oriented worldview as a barrier. } \\
\text { Limits to growth on a finite planet. } \\
\text { Dependence on nature. } \\
\text { Importance of governance. }\end{array}$ & $\begin{array}{l}\text { Nature has intrinsic value. } \\
\text { Justice for people and justice for the } \\
\text { natural environment. } \\
\text { Respect. } \\
\text { Social equity. } \\
\text { An ethical worldview is central to } \\
\text { sustainability. }\end{array}$ & $\begin{array}{c}1 \\
\text { Strong ecocentric ethic. }\end{array}$ \\
\hline $\mathrm{J}$ & $\begin{array}{c}\text { Quadruple bottom line (economic, social, environment, } \\
\text { governance) } \\
\text { Business perspective only provided. } \\
\text { Against transformational change preferring small } \\
\text { incremental change. } \\
\text { Emphasised innovation, management, leadership, staff } \\
\text { training and rewards, and collaboration and } \\
\text { communication with the government as the path to } \\
\text { sustainability. } \\
\text { First mover motivation to build a brand. } \\
\text { Reduce consumption of natural and financial } \\
\text { resources, and recycle. }\end{array}$ & $\begin{array}{l}\text { Need charity from the business. } \\
\text { Ethical business. } \\
\text { Obligation to reduce resource use. }\end{array}$ & $\begin{array}{l}12 \\
\text { Business-focused view of ethics and } \\
\text { path to sustainability. }\end{array}$ \\
\hline K & $\begin{array}{l}\text { Nature as a stock of resources. } \\
\text { Sustainable use over the long term. } \\
\text { Balance needs with resource availability. } \\
\text { Measurement, reporting and feedback loop integral to } \\
\text { the transformation to sustainability. }\end{array}$ & $\begin{array}{c}\text { Ethical path to sustainability } \\
\text { affected by culture and moral } \\
\text { values. }\end{array}$ & $\begin{array}{c}11 \\
\text { Human focused conceptualisation. }\end{array}$ \\
\hline $\mathrm{L}$ & $\begin{array}{l}\text { Managerial and business focus. } \\
\text { Population control. } \\
\text { Strong government and management. } \\
\text { Zero negative environmental impacts. } \\
\text { Stocks of resources. } \\
\text { Carbon footprints. }\end{array}$ & Conservation ethic. & $\begin{array}{l}\mathbf{9} \\
\text { Business-focused ethic and } \\
\text { managerial view of sustainability. }\end{array}$ \\
\hline
\end{tabular}

Source: Prepared for this research. 
There are two vertical columns to Cognitive Map A. The first column reflects organisational sustainability, and the second column adds the personal sustainability component. The organisational sustainability column flows sequentially through the five boxes in the left-hand column. The personal sustainability column flows through the three boxes in the right-hand column. Finally, the cognitive map flows horizontally from the box labelled '2. Economic' to the 'Personal/Individual' box in the right hand column.

This map shows the three-dimensional (three pillar) conception of sustainability in the first frame and structures the conceptualisation of sustainability around these social, economic and environmental components. This expert described the economic goals, such as profit and growth, without negative environmental or social impact, thereby rejecting the idea that negative social or environmental impacts can be traded off against positive economic outcomes. Consistent with the strong governance theme depicted later in the figure showing sustainability themes included in the 12 experts' conceptualisations, this expert believes environmental goals are achieved through compliance and management rather than by leaving natural systems free from human interference. The social component of sustainability is reflected by the social impacts on the individual at work and in their personal lives with notions of happiness, sufficiency and doing no harm.

This expert conceptualised sustainability at both an individual and organisational level; identified sustainability action tools, such as formal education, workplace training and compliance; and emphasised ethical behaviours, such as not inflicting harm on people or the environment, and social responsibility. Sustainability was described using the language of business (profit, growth, compliance, product lifecycle), but this language was infused with strong moral boundaries regarding impacts to self, society or the environment, and the need for 'constant evolving mindfulness' at the personal level.

Cognitive Map B (Figure 2) has two sequential pathways flowing from bottom to top; that is from the two central and lowest placed cards at the base of the map, up through the four cards on the left-hand side of the map, and through the same two lowest cards up through the four cards on the right-hand side of the map. This expert identifies the traditional multidimensional view of sustainability, but expressed this using the compass model of sustainability [45]. The compass model identifies four elements of sustainability as being nature, economy, societal and individual well-being, occupying the hypothetical NESW points of a compass, which is similar to the familiar environmental, social and economic conception. This expert emphasised that sustainability is place-based and context-specific, which suggests a generic definition may not be useful when developing sustainability solutions to local problems. This expert also emphasised sustainability as a future and learning-oriented process of change. When describing their cognitive map, this expert emphasised the importance of identifying and implementing sustainability solutions, and the role of soft cognitive skills, such as learning processes, building social connections and relationships, and the need for equity and mutual benefit between stakeholders, as integral to the transformation to sustainability.

The expert who produced Cognitive Map C (Figure 3) arranged their concept cards as shown, but described their conceptualisation of sustainability by beginning with the 'Thinking' card, then moving to the 'Skills' card, 'Leadership' card and then through the cards numbered 1, 2 and 3 which formed the key pathway to sustainability. The card with four circles and the cards showing energy and emissions were then described by this expert, with the 'UN definition' card added towards the end of the interview, which was viewed as oversight by this expert. 


\section{Cognitive map B}

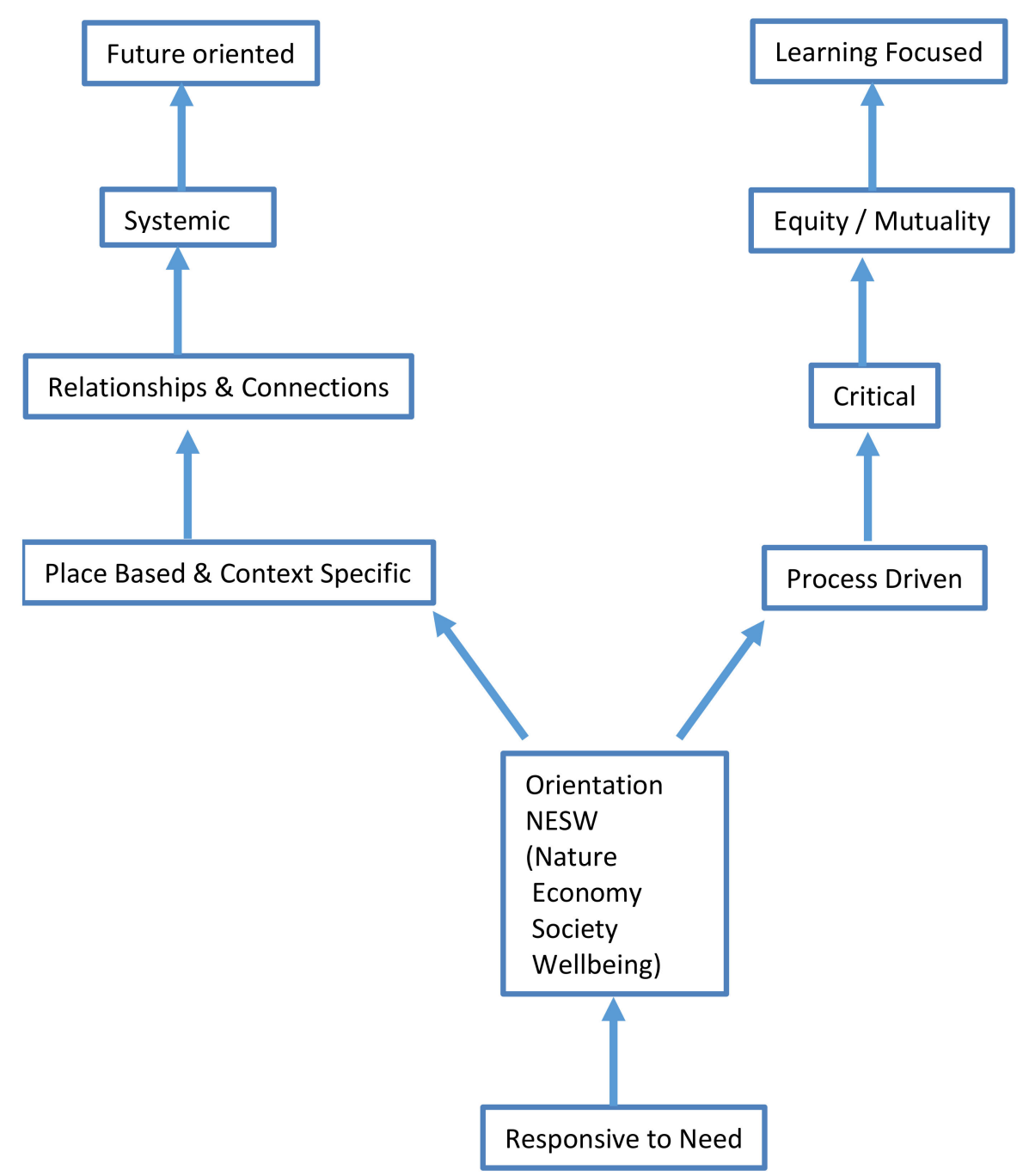

Figure 2. Cognitive Map B. Cognitive map prepared by Expert G.

Part II of Cognitive Map C was described as the pathway to sustainability. This expert began by identifying the types of thinking needed for transformation to sustainability, clearly distinguishing solution-based thinking from transformational thinking. This map also identifies the common three-dimensional sustainability conception, but places a fourth community engagement ring around the familiar economic, social and environmental components. This expert emphasises the ways of thinking which underpin the process of transformation to sustainability which requires creativity, reflection and critical thinking. Significantly this map identifies the definitional element of sustainability drawing on the WCED's needs based definition, as well as identifying three components of sustainability consisting of: (1) Understanding and knowledge; (2) attitudes, beliefs and values; and (3) actions. This layered conceptualisation informed the sustainability framework presented later in this paper.

This expert conceptualises sustainability as beginning with an understanding of problems and solutions, recognition of the need to connect with the natural environment, and a change in thinking embracing adaptation and transformation. The second step involves building a set of ethical values and beliefs, which would drive sustainability action. This expert utilised communitarian language, such as collaboration, partnership, engagement, social justice rather than the business language of 
corporatism to identify the essential issue of the connection between humankind and nature to drive sustainability transformation. The differentiation of sustainability actions from beliefs and values, and from the broader issue of human-environment connection provides a meaningful way to understand the underlying causes of different conceptualisations of sustainability.

\section{Cognitive map C}

I

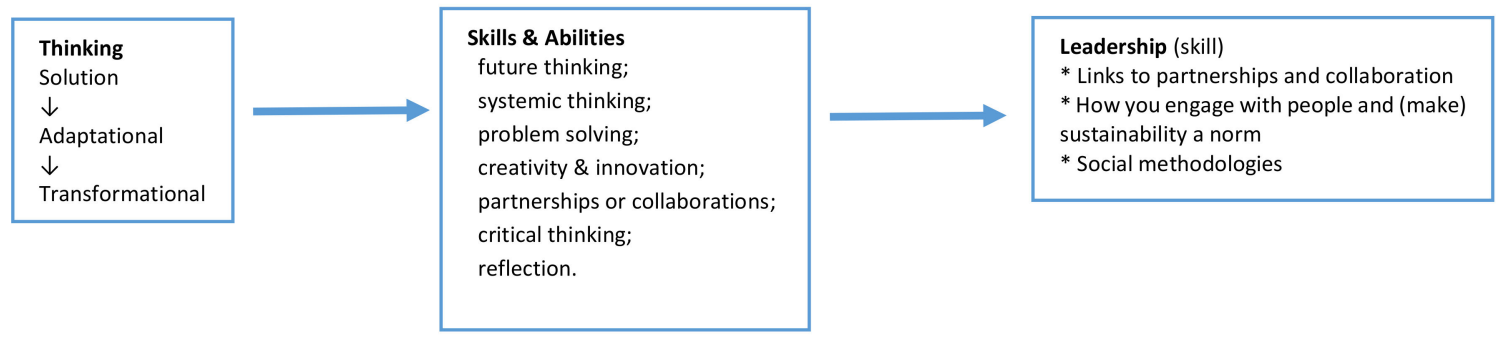

II

\begin{tabular}{|l|l|l|}
\hline $\begin{array}{l}\text { Understanding/Knowledge } \\
\text { Beyond 'solutions' and about } \\
\text { connection to the } \\
\text { environment and the bigger } \\
\text { picture }\end{array}$ & $\begin{array}{l}\text { (2) } \\
\text { Attitudes / Values / Beliefs } \\
\text { This is the necessary link to } \\
\text { lead to a change in actions }\end{array}$ \\
& $\begin{array}{l}\text { (3) } \\
\text { Actions (Sustainable } \\
\text { Practice) Often sit in } \\
\text { solutions and not in } \\
\text { transformational } \\
\text { change }\end{array}$ \\
\hline
\end{tabular}

III

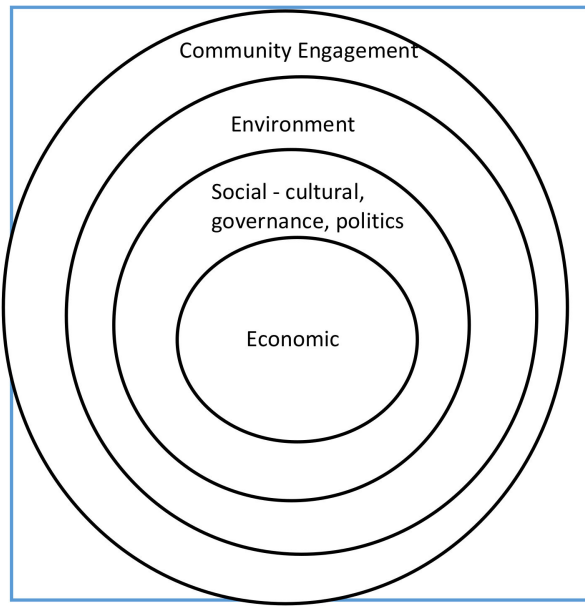

Energy \& Emissions Water

Biodiversity

Waste

Purchasing

Figure 3. Cognitive Map C. Cognitive map prepared by Expert F.

The three cognitive maps presented here demonstrate a diversity of content and conceptual meaning, but all include the reference to the three dimensions of economy, society and environment. However, this is just one element of how sustainability was conceptualised throughout the cognitive mapping process. Additionally, these three experts emphasised soft cognitive skills, including a dynamic learning process engaging debate at the professional level, rather than an emphasis on 
technological solutions to problems of unsustainability. The diverse ideas presented in these three cognitive maps are further explored later in this paper in the discussion of sustainability themes.

\section{Discussion}

In Table 2 we draw data from each expert's cognitive map and oral interpretation to provide a summary of the language and principles used to conceptualise sustainability (in the column headed Sustainability knowledge), as well as each expert's discussion of ethical concepts (in the column headed Ethical values. Each term listed in Table 2 was interpreted in the context of how it was used by the expert to conceptualise sustainability during their interview. Where the term was used critically or negatively, for example 'economic growth as a barrier to sustainability', or 'economic growth exceeds ecological limits', the expert's intended meaning is noted in the table.

We use the analysis summarised in Table 2 to locate each expert along an ecocentric-sustaincentric-technocentric paradigmatic scale (refer Figure 4). Initially, each expert was placed within one of the three paradigms based on the alignment of their conceptualisations to that specific paradigm. Ethical values were evident from experts' use of and emphasis on moral languages, such as equity, responsibility, respect, and charity. For example, experts who perceive nature as a stock of resources, focus on technological solutions to environmental problems, and/or emphasise economic outcomes, locate toward the technocentric end of the scale. A technocentric ethic is strongly anthropocentric, and evidenced by experts' perception of humans as separate from nature which is perceived as stocks of resources for human use, the use of cost-benefit analysis to make the business case for sustainability, and/or a focus on economic growth and technological advancement. Experts emphasising stewardship and protection of non-humans, intergenerational equity, and social wellbeing and equity, locate more centrally at the sustaincentric position on the scale. Conceptualising sustainability with reference to nature's intrinsic value, humankind's dependence on nature, and/or the preservation of nature as the primary objective align with an ecocentric worldview.

\begin{tabular}{|l|cccccccccccccc|}
\hline I & F & H & E & G & B & A & C & L & D & K & J \\
\hline Ecocentrism & Sustaincentrism & & & & Technocentrism & \\
\hline
\end{tabular}

Source: prepared for this research

Figure 4. Location of each expert along the paradigmatic scale.

Within these initial groupings, experts were further differentiated based on the strength and consistency of the sustainability principles they presented. For example, some experts predominantly used the managerial language of business to describe sustainability (e.g., profit, economic growth, efficiency) whereas, other experts emphasised the softer social skills (e.g., relationships, connection, mutual benefit), whereas, others used a more ecologically focused language (e.g., balance of nature, carbon footprints and nature's intrinsic value).

Eleven of the 12 experts conceptualised sustainability within an anthropocentric (sustaincentric or technocentric) worldview, and only one of the 12 experts displayed an ecocentric worldview. Expert I emphasised the importance of maintaining harmony and balance within nature by understanding limits to economic growth on a finite planet, as well as the central idea of ecocentrism, which is recognition of nature's intrinsic value separate from human instrumental use. Ecological and social justice, respect and social equity were ethical themes expressed by expert I when conceptualising sustainability.

Experts $\mathrm{J}$ and $\mathrm{K}$ were located at the technocentric and strongly anthropocentric end of the paradigmatic scale. Expert J conceptualised sustainability solely as a business objective, warned against rapid transformational change which may cause negative economic impact, and used the 
managerial language of business leadership and training to describe the preferred path to sustainability. This expert's ethical commitment was expressed in the obligation to reduce resource use and the need for business to act ethically through, for example, voluntary charitable activities. Expert $\mathrm{K}$ identified sustainable resource use, and sustainability measurement and reporting in a strongly human-focused conceptualisation.

Located more centrally along the scale and aligned with the sustaincentrism paradigm, were experts $\mathrm{H}$ and $\mathrm{F}$. These two experts displayed evidence of strong "sustainability thinking" in their use of sustainability language and concepts. For example, expert $\mathrm{H}$ identified the need for equality between human and environmental interests, rejecting a solely human-centred worldview. $\mathrm{H}$ also emphasised humankind's interconnection with nature and the need for holistic, systems thinking. However, $\mathrm{H}$ also perceived nature as a stock of capital for human use, reflecting an inherently anthropocentric ethic. Expert $\mathrm{F}$ identified the need for a strong environmental ethic to inform human action given humankind's connection with, and dependence on holistic natural systems. This expert also conceptualised sustainability using the ethical language of responsibility, justice and respect for holistic natural systems.

The remaining seven experts were located towards the technocentric end of the scale. Whilst showing strong anthropocentric values, their conceptualisations also reflected ideas consistent with sustaincentrism, such as the ethic of causing no social or environmental harm, an emphasis on both strong social and environmental responsibility; and the recognition of limits to growth on a finite planet and the intergenerational responsibility this creates. It is of course, not surprising given these participants were chosen for this research based on their professional specialisation in sustainability, that their conceptualisations reflected features of the sustaincentrism paradigm.

In the next section, we identify the full range of themes presented by the experts in the 12 cognitive maps.

\subsection{Sustainability Themes}

Diversity is a key element of the experts' conceptualisations. This diversity is depicted in Figure 5 as a summary of the range of ideas contained in the 12 cognitive maps, which shows elements of sustainability most repeated in larger fonts.

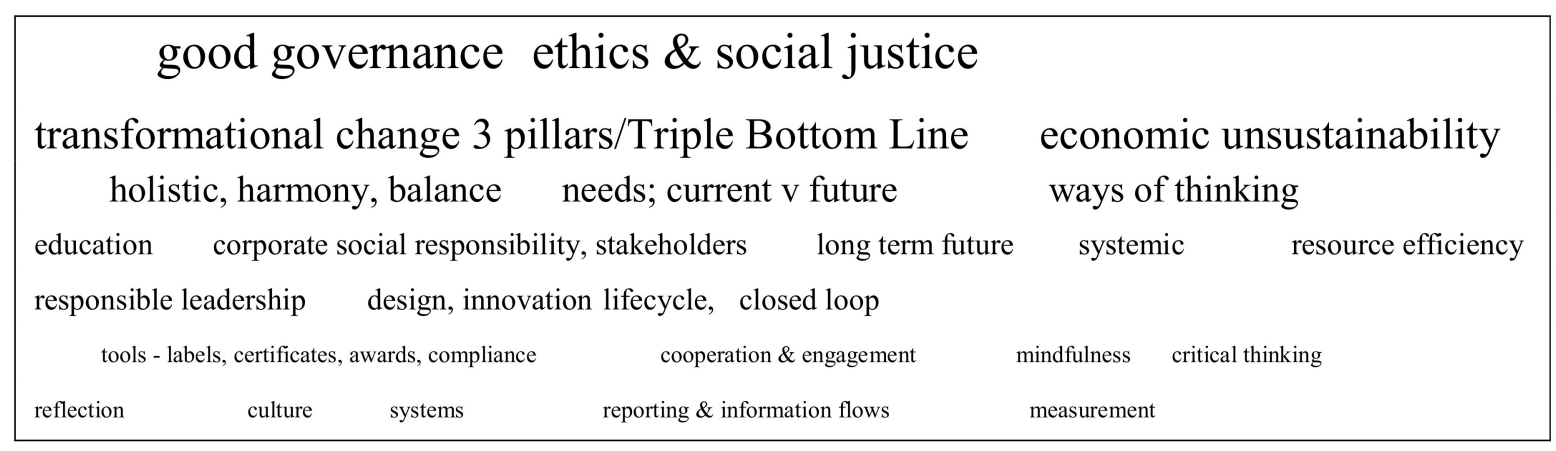

Source: prepared for this research

Figure 5. Sustainability themes included in the 12 experts' conceptualisations.

Figure 5 provides a thematic scatter showing the diverse elements of sustainability conceptualised by the 12 experts. The need to govern for sustainability in a way which is both ethical and just was the major recurring theme, suggesting the view that humankind will not transition to sustainability if left for example, to unmanaged market forces and individual self-interest. Other repeated themes were the unsustainability of current economic systems, the traditional environmental, social and economic (three-pillar) conception of sustainability and the major transformational change that sustainability represents. Education, design and innovation were themes repeated as enabling forces 
for sustainability. The importance of the underlying worldview (or 'ways of thinking'), the moral dimension of sustainability, and sustainability as an integrated, holistic concept were also themes repeated by experts.

None of the themes depicted in Figure 5 is new to the sustainability discourse. Although many of these themes are common and well established within the literature, the thematic scatter shows that according to these 12 experts, sustainability is much more than the traditional three-pillar or needs-based concept. The requirement for decision makers to lead within their organisations and local communities, to comply with environmental regulation, to measure performance towards relevant sustainability goals, to reward and certify sustainability actions, and to engage and cooperate with stakeholders, displays the complexity and breadth of participation that sustainability demands. The experts conceptualised sustainability as an evolving learning process requiring adaptation, collaboration, innovation and critical reflection to enable transformational change away from entrenched, unsustainable economic impacts.

Although the traditional multidimensional view of sustainability was strongly reflected in the experts' conceptualisations; scale, change processes, and temporal and spatial contexts, as predicted by Hahn et al. [22], were also differentiating factors. The difference in scale is seen in conceptualisations at the personal, local, organisational and global levels. Transformational change and the policy instruments required to drive change are common themes noted in Figure 5. Intergenerational (temporal) justice, and strong ethical, social justice and equity (spatial) themes were also evident.

The business case and managerial view of sustainability are evident in experts' conceptualisations located at the technocentric end of the paradigmatic scale (refer Figure 4), whereas, the more holistic or integrative [28] versions are central to experts' conceptualisations located in the sustaincentric central section of the scale. For example, both Experts G and F (refer Table 2) form conceptualisations where both environmental and social elements are synthesised into a holistic vision emphasising social welfare, social responsibility, social justice and social equity, and our relationships with each other and with the natural environment. In this study, no expert specifically referred to sustainability as a journey, but the process of transformational change was one of the most common themes expressed by experts.

To further refine the many diverse sustainability themes presented in Figure 5, we categorised these themes as focused either on theoretical or practical, action-based aspects of sustainability (see Figure 6). Sustainability theory is reflected in the core objective(s) being pursued [46], and underlying worldview which includes the knowledge base, cultural views and underlying values [36]; and sustainability practice is represented as a series of actions to achieve sustainability, some of which must be transformative in nature [47].

Fundamentally, sustainability is about sustaining something. Often this something is the longevity of the human species; however, the natural environment, economic wealth or societal wellbeing, for example, might also be considered as a primary focus of sustainability. Identification of a core objective is dependent on the dominant worldview informed by our knowledge, cultural influences and moral values. The core objective presented in Figure 6 was drawn from the 12 cognitive maps as an example only, as it represents only one of many possible objectives that could be drawn from the expert's cognitive maps.

The identification of what the pursuit of sustainability is trying to achieve is inherently ontological as it depends on our understanding of the nature of our existence and the connection of humankind with the rest of (nonhuman) nature. An anthropocentric objective, such as prioritising the long-term survival of the human species ahead of other species with which we co-exist, is derived from a worldview which assumes humankind possesses deterministic power to shape our future. This ability is very much dependent on the reality of humankind's connection with the rest of nonhuman nature, and it is our understanding of this interdependence where differences lie. By contrast, an ecocentric worldview would inform a core sustainability objective that prioritises the preservation of the ecological community ahead of any individual species. 


$\begin{array}{ll}\text { Core objective } & \text { Worldview } \\ \text { Meeting current and long- } & \text { Knowledge } \\ \text { term future needs by } & \text { TBL/3 pillar definition, } \\ \text { efficient and sustainable use } & \text { holistic systems, } \\ \text { of resources. } & \text { Values } \\ & \text { ethics \& social justice, } \\ & \text { social responsibility to stakeholders, } \\ & \text { harmony, balance } \\ & \text { Culture } \\ & \text { ways of thinking } \\ & \text { mindfulness }\end{array}$

Action

Education

Innovation

Design

lifecycle,

closed loop

\section{Governance}

leadership,

labels, certificates, awards

compliance,

cooperation \& engagement,

information flows,

measurement

\section{Change}

process of transformation

Figure 6. The categorisation of themes from the sustainability schematic scatter. Source: Prepared for this research.

Sustainability practice is reflected in the implementation or action phase aimed at achieving sustainability, or at least reducing unsustainability, which includes policy settings, managerial decision-making, governance processes, and design of new technologies which are all underpinned by education systems required to drive transformational and generational change.

\subsection{Sustainability Conceptualisation Framework}

The analysis of experts' sustainability conceptualisations, whilst confirming the centrality of their individual worldviews to those conceptualisations, also revealed two additional layers of meaning, reflected by the assumed primary objective of sustainability and the range of recommended actions to achieve sustainability. Figure 7 provides a framework depicting these three layers of meaning.

The framework depicted in Figure 7 represents a further refinement of the thematic analyses presented in Figures 5 and 6. It distinguishes three separate layers of meaning to any sustainability conceptualisation broadly distinguished as

1. The core objective of long term survival;

2. The underlying worldview which informs the conceptualisation; and

3. Action mechanisms used to progress towards sustainability.

The innermost circle represents the core objective of sustainability. Lam et al. [48] describe this core meaning as a condition or state of a system, whereas, Davidson [49] refers to sustainability literally as the capacity to endure. This core objective is usually expressed as an objective to sustain something, and it is this something which is contested. Hence, the critical question concerns what is to be sustained in the long term which, if applied exclusively to the human species, means that the core objective of sustainability is our long-term survival. This contrasts with Sterling [50] who defines sustainability as the survival, security and well-being of a whole system rather than any specific species. There is substantial variation as to which species and which systems (natural and/or social) ought to be 
sustained, and for how long [51]; hence, the primary objective of sustainability is very much contested. The inner circle of the framework does not privilege the survival of any specific species or system, but rather recognises and accommodates this diversity of views.

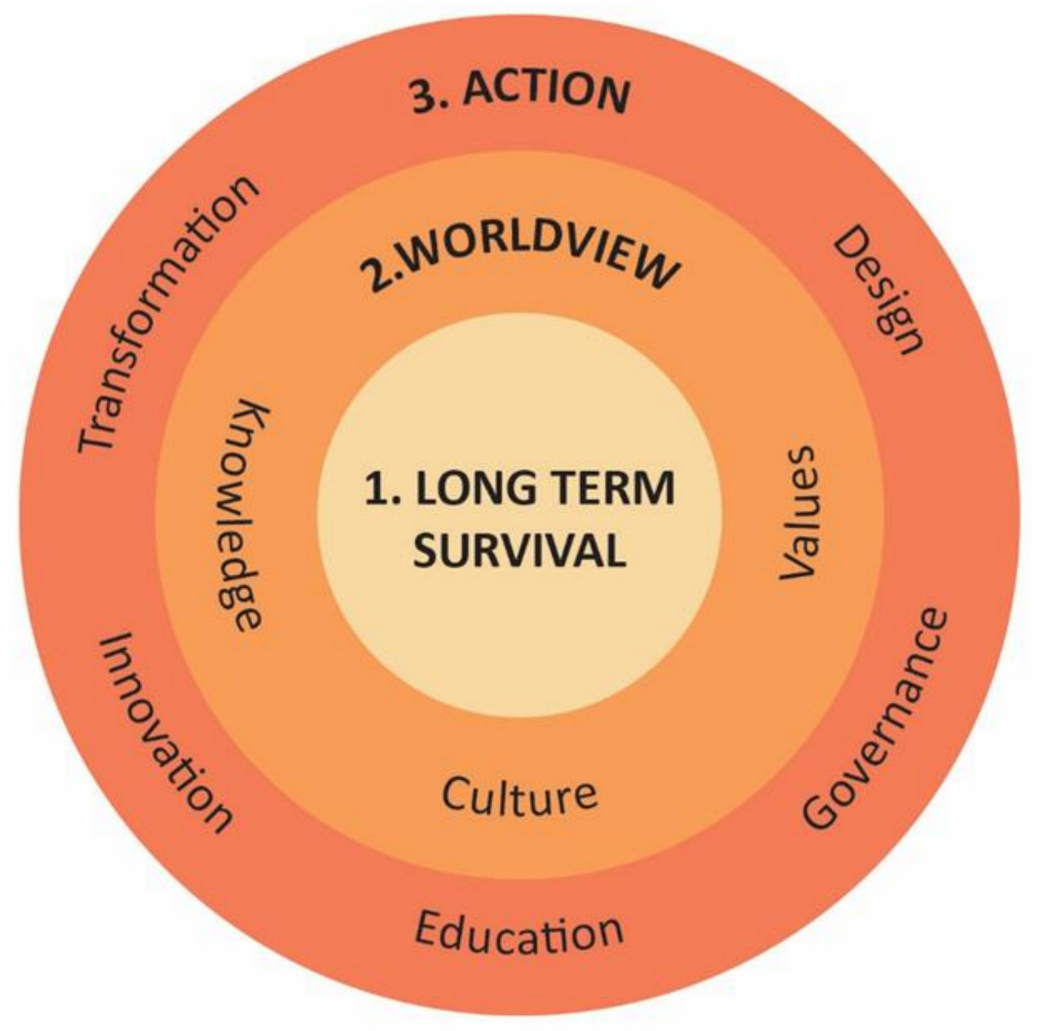

Figure 7. Sustainability conceptualisation framework. Source: Prepared for this research.

Interconnected with long term survival goals are the common three dimensional and needs-based definitions of sustainability. Each of the 12 experts conceptualised sustainability as containing some version of environmental, social and economic elements. Environmental preservation, societal well-being and a strong economy all have clear and strong connections to the long-term survival of humankind. Needs-based definitions of sustainability are also closely connected to long term survival objectives given they include considerations of intergenerational trade-offs between current and future needs, and the survival of systems required to meet these needs, where meeting the needs of those species whose survival is prioritised determines their quality and length of life. The expert participants also identified the efficient use of resources as being a goal of sustainability, in recognition of the conservational element required for survival beyond the short term. The core sustainability objective reflected in Cognitive Map A is the need to operate a growing, profitable business which does not harm people or environment; whereas, Cognitive Maps B and C identify the primary objective of meeting human needs.

The second layer of Figure 7 represents the knowledge base and cultural views, and the ethical and philosophical values on which the conceptualisation of sustainability is based. The ideas which occupy this second layer are inherent or embedded in the dominant worldview, which is determined by cultural conditioning, social roles, life experiences and our understanding of the truth [5]. The dominant worldview determines our value system and our perceived relationship with nature [20]. Hence, an individual's conceptualisation of sustainability is inherently dependent upon their specific worldview [11]. This worldview may be the Western technocentric worldview, which steers discussions of solutions to unsustainability towards economic incentives and technological innovation. Bonnett [37] frames the discussion of the meaning of sustainability in terms of humankind's relationship with nature, 
distinguishing the shorter term 'sustainability agenda' whereby we endeavour to reduce our impact on nature, from the essential and more important longer term need of developing a true connection with and an understanding of our place in the natural world.

There is a broad and diverse set of ethical values that inform the sustainability debate [52], but as they tend not to be clearly visible, they often escape essential critique and revision. A more ecocentric view of sustainability will emphasise the need for change in humankind's relationship with the natural world and the need, for example, to change lifestyle and consumption patterns [53]. The expert from the education sector who produced cognitive map C emphasised humankind's connection to the environment as the key knowledge element of sustainability; whereas, in cognitive map A, humankind's relationship with nature is expressed in terms of the ethical principle of doing no harm, but within a technocentric worldview, which focuses on economic growth and profitability; and the expert participant who prepared Cognitive Map B emphasised ethical, social relationships and connections with both community and environment as essential to sustainability.

The outer layer of Figure 7 is the action level where sustainability education, policy and practice occur. Action mechanisms are activated at this level where decision makers are confronted with complex causes of unsustainability and a diverse array of tools to drive the transformation to sustainability. At this level, sustainability requires a diverse range of education, innovation, design, governance initiatives to drive the process of transformation to sustainability. Each of the 12 cognitive maps includes some of these action tools representing each expert's views as to how sustainability could be achieved at the operational level. This outer layer is readily observable as sustainability policy and practice, whereas, the two inner layers a more strongly connected to sustainability theory.

The sustainability framework reflects the centrality of a dominant worldview, and therefore, the significance of ethical values, culture and knowledge to deriving sustainability meaning. However, despite the identification of three layers of meaning to sustainability conceptualisations, each layer is connected with, rather than separate to other layers. For example, the dominant value system is reflected in the worldview, and will strongly influence the core objective of and preferred actions to achieve sustainability. If the objective is long term survival of humankind, then this reflects an anthropocentric ethic and worldview, and this will lead to the selection of sustainability policies and actions that protect human interests ahead of the welfare of other species. Interconnection, as a core principle, is essential to any conceptualisation of sustainability.

The framework developed in this research helps clarify competing and contested versions of sustainability within one common theoretical framework, by distinguishing the various layers of meaning embedded in the sustainability concept. The significance of the underlying worldview to the chosen conceptualisation, emphasises the need for this to be visible and understood when discussing sustainability theory, or developing policy. Such a framework should prove useful for understanding the underlying causes of different views held by competing interest groups, as well as providing a mechanism for developing new context-specific definitions of sustainability, such as those used in business and government. Whether this is a desired use of the framework is in itself contested and dependent on our view as to the desirability and consequences of many diverse and contested meanings.

Gale et al. [54] hope for a much greater commitment within education to sustainability learning "from a deep, interdisciplinary engagement across ontological perspectives, epistemological claims, and political interests ..." (p. 259). The sustainability framework should also prove useful as an educational tool to support the role of educators to inform students of the diversity of meaning of sustainability, so they can debate and evaluate the strength of competing views, thereby contributing to the evolution of the sustainability concept. Inherent in the sustainability framework is the need to establish core objectives, to understand the dominant worldview, which includes cultural and ethical values, and to understand the practical mechanisms where sustainability action takes place. Within a learning environment, prior to educating for sustainability, foundational learning in alternative worldviews, including normative and cultural influences is required, so that the contested nature of 
the concept is clearly understood prior to committing to any specific conceptualisation. Attaining epistemic cognition of the connection between an underlying worldview and sustainability knowledge is an enormous educational challenge, requiring worldviews to be challenged, and where needed changed, to facilitate the transformation to sustainability [34]. The sustainability framework could also form the basis for future empirical studies of worldviews, including moral values, cultural norms, beliefs and attitudes towards sustainability, that were observed in this study.

This research and its findings are limited by the small sample of expert participants, and limitations in time and resources available to investigate an extremely complex concept, such as sustainability. The strength of the sustainability framework, which is the apparent simplicity of visualizing a complex idea in summary graphical form, is also a weakness, as the three-layered conceptualisation suggests separation when sustainability is inherently an integrated concept. The connection between all elements of sustainability is a complicating factor, and any apparent separation must be approached cautiously.

\section{Conclusions}

The cognitive mapping methodology used in this research produced 12 unique conceptualisations of sustainability, each underpinned by the expert's personal worldview. Each of these worldviews was examined for sustainability language and principles, and ethical values, and ranked along a paradigmatic scale centred around sustaincentrism. Many common themes were drawn from the 12 cognitive maps, and further analysis led to the development of a sustainability conceptualisation framework. This framework conceptualises sustainability as complex, dynamic and evolving with three distinct layers which include a primary objective connected to long term survival; an underlying worldview which includes values, beliefs, cultural understanding and core knowledge; and an implementation layer where sustainability action occurs. This framework contributes to a better understanding of sustainability as it enables the source of differences in meaning to be more clearly identified and understood. For example, conceptualisations that begin with entirely anthropocentric based objectives will differ from those that recognise nature's intrinsic value. Similarly, technologically based worldviews lead to different conceptualisations of sustainability than those developed within nature-based indigenous societies, and these different conceptualisations cannot be reconciled without first examining the underlying core objective, worldview and action mechanisms contained within each.

The sustainability framework, by clarifying conceptual differences that underpin various definitions of sustainability, not only will help educators and students navigate through the multiplicity of sustainability meanings, but has the potential to identify the source of conflict between competing interest groups, by clarifying the causes of different viewpoints; and provide a conceptual tool to develop unique or contextually-based definitions, such as specific governmental, corporate or industry-based definitions. Whether this framework does prove useful for these or other purposes needs to be the focus of further research.

Supplementary Materials: All 12 cognitive maps are available online at http://www.mdpi.com/2071-1050/12/5/ 1977/s1.

Author Contributions: P.W. was responsible for the research design, data collection and analysis and preparation of the cognitive maps. G.L. was responsible for data analysis, project overview and publication of results. All authors have read and agreed to the published version of the manuscript.

Funding: This research received no external funding.

Conflicts of Interest: The authors declare no conflict of interest.

\section{References}

1. UNCSD. Report of the United Nations Conference on sustainable development; UNCSD: Rio de Janeiro, Brazil, 2012.

2. Ekins, P.; Gupta, J.; Boileau, P. Global Environment Outlook GEO-6: Healthy planet, Healthy people. Available online: https://wedocs.\%20unep.\%20org/bitstream/handle/20.500. (accessed on 15 January 2020). 
3. Smith, P.A.C.; Sharicz, C. The shift needed for sustainability. Learn. Organ. 2011, 18, 73-86. [CrossRef]

4. Giovannucci, D.; Potts, J. Seeking Sustainability, COSA Preliminary Analysis of Sustainability Initiatives in the Coffee Sector; International Institute for Sustainable Development: Winnipeg, Canada, 2008.

5. Byrch, C.; Kearins, K.; Milne, M.; Morgan, R. Sustainable "what"? A cognitive approach to understanding sustainable development. Qual. Res. Account. Manag. 2007, 26-52. [CrossRef]

6. Wals, A.E.; Jickling, B. Sustainability in higher education. Int. J. Sustain. High Educ. 2002, 3, $221-232$. [CrossRef]

7. Van der Byl, N.S. Embracing tensions in corporate sustainability: A review of research from win-wins and trade-offs to paradoxes and beyond. Organ. Environ. 2015, 28, 54-79. [CrossRef]

8. Ferdig, M.A. Sustainability Leadership: Co-Creating a Sustainable Future. J. Chang. Manag. 2007, 7, 25-35. [CrossRef]

9. Manderson, A.K. A systems based framework to examine the multi-contextural application of the sustainability concept. Environ. Dev. Sustain. 2006, 8, 85-97. [CrossRef]

10. Gatto, M. Sustainability: Is it a Well Defined Concept? Ecol. Appl. 1995, 5, 1181-1183.

11. Wiersum, K.F. 200 Years of Sustainability in Forestry: Lessons from History. Environ. Manag. 1995, 19, 321-329. [CrossRef]

12. Brundiers, K.; Wiek, A. Educating students in real-world sustainability research: Vision and implementation. Innov. High. Educ. 2011, 36, 107-124. [CrossRef]

13. Lankoski, L. Alternative conceptions of sustainability in a business context. J. Clean. Prod. 2016, 139, 847-857. [CrossRef]

14. Marshall, J.D.; Toffel., M.W. Framing the elusive concept of sustainability: A sustainability hierarchy. Am. Chem. Soc. 2005, 39, 673-682. [CrossRef] [PubMed]

15. Schilleman, B.; Gough, J. Sustainability in your words. Inst. Transp. Eng. 2012, 82, 20-24.

16. Redclift, M. Sustainable development (1987-2005): An oxymoron comes of age. Sustain. Dev. 2005, 13, 212-227. [CrossRef]

17. Bonnett, M. Education for sustainability as a frame of mind. Environ. Educ. Res. 2002, 8, 9-20. [CrossRef]

18. Luke, T. Neither sustainable nor development: reconsidering sustainability in development. Sustain. Dev. 2005, 13, 228-238. [CrossRef]

19. Connelly, S. Mapping sustainable development as a contested concept. Loc. Environ. 2007, 12, $259-278$. [CrossRef]

20. Tabara, J.D.; Pahl-Wostl, C. Sustainability learning in natural resource use and management. Ecol. Soc. 2007, 12, 3. [CrossRef]

21. Meadows, D.H.; Meadows, D.L.; Randers, J.; Behrens, W.W. The limits to growth; Potomac Associates: Falls Church, VA, USA, 1972.

22. Hahn, T.; Pinkse, J.; Preuss, L.; Figge, F. Tensions in corporate sustainability: Towards an integrative framework. J. Bus. Ethic. 2015, 127, 297-316. [CrossRef]

23. Ketschau, T.J. Social sustainable development or sustainable social development-two sides of the same coin? The structure of social justice as a normative basis for the social dimension of sustainability. Int. J. Design Nature Ecodyn. 2017, 12, 338-347. [CrossRef]

24. Kioupi, V.; Voulvoulis, N. Education for Sustainable Development: A Systemic Framework for Connecting the SDGs to Educational Outcomes. Sustainability 2019, 11, 6104. [CrossRef]

25. Milne, M.J.; Kearins, K.; Walton, S. Creating adventures in wonderland: The journey metaphor and environmental sustainability. Organization 2006, 13, 801-839.

26. Painter-Morland, M.; Demuijnck, G.; Ornati, S. Sustainable development and well-being: A philosophical challenge. J. Bus. Ethic. 2017, 146, 295-311. [CrossRef]

27. Grober, U. Sustainability: A Cultural History. Green: Devon, UK, 2012.

28. Hahn, T.; Preuss, L.; Pinkse, J.; Figge, F. Cognitive frames in corporate sustainability: Managerial sensemaking with paradoxical and business case frames. Acad. Manag. Rev. 2014, 39, 463-487. [CrossRef]

29. Sinakou, E.; Donche, V.; Boeve-de Pauw, J.; Van Petegem, P. Designing Powerful Learning Environments in Education for Sustainable Development: A Conceptual Framework. Sustainability 2019, 11, 5994. [CrossRef]

30. Decuypere, M.; Hoet, H.; Vandenabeele, J. Learning to Navigate (in) the Anthropocene. Sustainability 2019, 11, 547. [CrossRef] 
31. Schlaile, M.P.; Urmetzer, S.; Blok, V.; Andersen, A.D.; Timmermans, J.; Mueller, M.; Fagerberg, J.; Pyka, A. Innovation Systems for Transformations towards Sustainability? Taking the Normative Dimension Seriously. Sustainability 2017, 9, 2253.

32. Norton, B.G. Toward Unity among Environmentalists; Oxford University Press: Oxford, UK, 1991.

33. Bawden, R. The community challenge: The learning response. In Social learning systems and communities of practice; Springer: London, UK, 2010; pp. 39-56.

34. Kitchener, K. Cognition, metacognition, and epistemic cognition. Hum. Dev. 1983, 26, 222-232. [CrossRef]

35. Van Egmond, N.D.; De Vries, H.J.M. Sustainability: The search for the integral worldview. Futures 2011, 43, 853-867. [CrossRef]

36. Hedlund-de Witt, A. Exploring worldviews and their relationships to sustainable lifestyles: Towards a new conceptual and methodological approach. Ecol. Econ. 2012, 84, 74-83. [CrossRef]

37. Bonnett, M. Environmental education and the issue of nature. J. Curric. Stud. 2007, 39, 707-721. [CrossRef]

38. Gladwin, T.N.; Kennelly, J.J.; Krause, T.S. Shifting paradigms for sustainable development: Implications for management theory and research. Acad. Manag. Rev. 1995, 20, 874-907. [CrossRef]

39. Leopold, A. A Sand County Almanac, and Sketches Here and There; Oxford University Press: New York, NY, USA, 1989.

40. Laureano-Cruces, A.L.; Ramirez-Rodriguez, J.; Mora-Torres, M.; de Arriaga, F.; Escarela-Perez, R. Cognitive-Operative Model of Intelligent Learning Systems Behaviour. Interact. Learn. Environ. 2010, 18, 11-38. [CrossRef]

41. Tegarden, D.P.; Sheetz, S.D. Group cognitive mapping: a methodology and system for capturing and evaluating managerial and organizational cognition. Omega 2003, 31, 113-125. [CrossRef]

42. Kaplan, S.; Kearney, A.R. Toward a methodology for the measurement of knowledge structures of ordinary people: The conceptual content cognitive map (3CM). Environ. Behav. 1997, 29, 579-617.

43. Ruiz-Primo, M.; Shavelson, R.; Li, M.; Schultz, S. On the validity of cognitive interpretations of scores from alternative concept-mapping techniques. Educ. Assess. 2001, 7, 99-141. [CrossRef]

44. Nowell, L.S.; Norris, J.M.; White, D.E.; Moules, N.J. Thematic Analysis: Striving to Meet the Trustworthiness Criteria. Int. J. Qual. Meth. 2017, 16, 1-13. [CrossRef]

45. Kapitulčinová, D.; AtKisson, A.; Perdue, J.; Will, M. Towards integrated sustainability in higher education-Mapping the use of the Accelerator toolset in all dimensions of university practice. J. Clean. Prod. 2018, 172, 4367-4382. [CrossRef]

46. Vos, R.O. Defining sustainability: a conceptual orientation. J. Chem. Tech. Biotech. 2007, 82, 334-339. [CrossRef]

47. Etzion, D.; Gehman, J.; Ferraro, F.; Avidan, M. Unleashing sustainability transformations through robust action. J. Clean. Prod. 2017, 140, 167-178. [CrossRef]

48. Lam, J.; Walker, R.; Hills, P. Interdisciplinarity in sustainability studies: A review. Sustain. Dev. 2014, 22, 158-176. [CrossRef]

49. Davidson, K. A typology to categorize the ideologies of actors in the sustainable development debate. Sustain. Dev. 2014, 22, 1-14. [CrossRef]

50. Sterling, S. Learning for resilience, or the resilient learner? Towards a necessary reconciliation in a paradigm of sustainable education. Environ. Educ. Res. 2010, 16, 511-528. [CrossRef]

51. White, M. Sustainability: I know it when I see it. Ecol. Econ. 2013, 86, 213-217. [CrossRef]

52. Kassel, K. The circle of inclusion: sustainability, corporate social responsibility and the values that drive them. J. Hum. Value. 2012, 18, 133-146. [CrossRef]

53. Imran, S.; Alam, K.; Beaumont, N. Reinterpreting the definition of sustainable development for a more ecocentric reorientation. Sustain. Dev. 2014, 22, 134-144. [CrossRef]

54. Gale, F.; Davison, A.; Wood, G.; Williams, S.; Towle, N. Four Impediments to Embedding Education for Sustainability in Higher Education. Aust. J. Environ. Educ. 2015, 31, 248-263. [CrossRef]

(C) 2020 by the authors. Licensee MDPI, Basel, Switzerland. This article is an open access article distributed under the terms and conditions of the Creative Commons Attribution (CC BY) license (http://creativecommons.org/licenses/by/4.0/). 